\title{
LATIP 2021
}

International Conference on Language and Technology in the Interdisciplinary Paradigm

\section{DEVELOPMENT OF SOCIAL CAPITAL IN EDUCATIONAL PROCESS}

\author{
Anna Shutaleva (a, b)*, Evgeniya Putilova (c), Evgeniya Ivanova (d), Elena Melnikova (e), \\ Evgeny Knysh (f) \\ *Corresponding author \\ (a) Ural Federal University named after the first President of Russia B.N. Yeltsin, 51, Lenin Ave., Ekaterinburg, \\ Russia; ashutaleva@yandex.ru \\ (b) Ural State Law University, Ekaterinburg, 21, Komsomolskaya str., Ekaterinburg, Russia; \\ (c) Ural Federal University named after the First President of Russia B N Yeltsin, Nizhniy Tagil Technological \\ Institute, 59, Krasnogvardeyskaya str., Nizhniy Tagil, Russia; eazhiltsova@mail.ru \\ (d) Ural Federal University named after the first President of Russia B.N. Yeltsin, 51, Lenin Ave., Ekaterinburg, \\ Russia; ieviev@mail.ru \\ (e) Ural Federal University named after the first President of Russia B.N. Yeltsin, 51, Lenin Ave., Ekaterinburg, \\ Russia; leykande@yandex.ru \\ (f) Ural State Law University, Ekaterinburg, 21, Komsomolskaya str., Ekaterinburg, Russia; gratamor@gmail.com
}

\begin{abstract}
The article is devoted to educational opportunities for the formation of social capital. Social capital is manifested in the ability of people to communicate and work together. Analysis of the concept of social capital allows understanding the foundations of social interaction, the need for trust, and the relationship between the formation and distribution of the social trust, norms, and social capital itself. Social capital does not exist outside people. Social capital cannot be characterized as an attribute of a separate individual. Social capital belongs to the group, the community. Learning is a situation of joint activity. In modern pedagogy, the problem is how to teach, organizing effective joint forms of educational activity. In distance learning (e-learning), it is important to organize the educational environment to have properties that make up for the lack of live communication. Today, the subjective nature of the educational process, focused on the formation of a creative personality, is being affirmed. Educational priorities are aimed at comfortable, conflict-free cooperation between the student at all levels of the educational process and the teacher, perhaps even partnership. The teacher and the student jointly develop goals, objectives, problem search field of research, working "cocreatively," a mini-team. This anthropocentric pedagogical technology relates to project and problem technologies in the educational process.
\end{abstract}

2357-1330 @ 2021 Published by European Publisher.

Keywords: Communication, education, project, problem technologies, social capital 


\section{Introduction}

In recent decades, social capital has become relevant for many philosophical, sociological, and economic studies. This term was introduced back in the 19th century. One of the main problems in understanding social capital is the lack of a unified approach, caused by the duality of understanding the phenomenon under study. Most researchers note the duality of social capital. Social capital is both a set of qualities, properties of interacting individuals, and attributes of the environment in which individuals act. One of the earliest significant studies and analyses of "social capital" was carried out by Hanifan (1916) and is defined as "significant circumstances affecting people's daily lives" to whose sympathy we attributed friendship, benevolence. Hanifan tried to identify ways to raise the level of social capital by analyzing those communities in the United States where the program of accessibility of primary and secondary education was implemented. As a result, there is an improvement in social welfare even in spheres not related to education. Hanifan advocated the development of social capital, believing that it is possible to achieve significant benefits. He concluded the need to develop the ability to build social relationships for each person.

Coleman (1988) tried to combine the concepts of social and human capital. Coleman (1988) defined social capital as a public good created by individuals in the name of profit. Coleman (1988) notes that it is difficult to define the concept of "social capital" accurately but notes its productivity because it contributes to achieving specific goals that cannot be achieved in its absence. A significant feature of social capital is its usefulness for the individual. Social ties acquire the status of capital only when they allow an individual to achieve a goal. Human capital manifests itself in knowledge and skills. Social capital manifests itself in relationships. The introduction of norms in society is a condition for the development of social capital. The moral norms of large and small groups induce its members to abandon interests in favor of the benefits for the collective. According to Coleman, social capital contributes to the containment of negative tendencies, deviations in groups, and the growth of positive intentions.

Coleman analyzed and proved the dependence of students' academic performance on the social capital of their family and the immediate environment. In cases where social ties were broken, academic performance dropped significantly. Coleman notes its closed nature as a system, arguing that it is necessary to form social capital. Coleman conducted a study and proved a direct correlation between social capital (inside and outside the family) and decreased the likelihood of school dropout. Coleman considers the main problem and threat to social capital because people who create it receive less from others. This process leads to insufficient "investment in social capital" (Coleman, 2001, p. 138).

Bourdieu identifies four main types of capital: economic (material wealth), cultural (education and culture), symbolic (reputation, image, person), and social. He defines social capital as "the totality of real or potential resources associated with the possession of a durable network of more or less institutionalized relationships of mutual acquaintance and recognition" (Bourdieu, 2012, p. 66). Bourdieu defined social capital as a network of social circles, as the observance of obligations. Bourdieu, like Coleman, also finds the basis of social capital in relationships that can only exist in practice. The dependence of social capital on economic and cultural capital and the impact on them are also noted. Social capital requires constant reproduction of relationships that determine norms and recognition. A group possessing social capital can 
delegate the right to act on its behalf to a separate representative, defining the boundaries of responsibility and standards of this association. Social capital is those opportunities that the group members have due to their belonging to it and that which are not present in the individuals who are not in the group. Each member of the group is interested in it because it brings benefits, but this requires maintaining a certain level of social ties, relationships, trust. The social capital of a group depends on the relations of this group and the economic, symbolic, and cultural capital of this group and individuals associated with it. The formation and source of the social capital of everyone is origin, family, study, i.e., everything that surrounds people.

Fukuyama asserts the need for social, moral restrictions as a condition for the joint existence of people. Norms restrict and bind people, regulate their behavior. They are informal and lead to cohesion, cooperation of people in a group. Fukuyama calls social capital "an irrational habit" and "an integral element of the correct functioning of modern and rationally arranged economic and political institutions" (Fukuyama, 2004). He argues that the existence of social capital is a person's need for the strength of his social nature. A person needs trust, which is both a source and a consequence of social capital. Grouping is the basis for the formation of social capital. In the case of negative actions within the group, a "gap" is possible, which reduces social capital. However, it cannot completely disappear due to the social need of individuals for trust, unification, for cooperation. For maintaining social capital in a group, commitments must be fulfilled, reciprocal norms must be respected, and opportunistic behavior must be avoided. Fukuyama approaches social capital using the example of society, rather than individual small groups, trying to analyze its connection with the problems of democracy, citizenship, and trust.

Patnam agrees with previous researchers that social capital makes it possible to achieve those impossible goals in the absence of it. He defines social capital as "features of social organization (principles, norms, structures) that are capable of strengthening the effectiveness of coordinated actions carried out by society" (Putnam, 1996). As a feature of social capital, he singles out the possibility of its growth with active use and disappearance when not used. Unlike material capital, social capital is common to the group and belongs to everyone. It is based on trust, and groups that maintain norms of reciprocity and respect are more successful in solving group problems when they arise. Trust, norms, and group structures constitute a stock of social capital that is capable of self-reproduction. Social capital is essential both for the economic well-being of society and for effective governance. Patnam identifies two components of social capital: cultural component (formation of norms, relationships, trust) and structural component (formal and informal social networks).

Patnam concludes that the group is capable of improving interaction when using similar norms and maintaining them. Trust, norms, cooperation, formed within the framework of one group, can eventually spread to society as a whole. Thinkers of the 20th and 21 st centuries regularly turned to the topic of social capital and associated their economic, sociological, philosophical, and political concepts with this term. All researchers note the importance of the family in the formation and distribution of social capital.

\section{Problem Statement}

The education system in Russia today is undergoing significant changes. The emergence and implementation of new educational standards require the use of project and problem-based education 
methods. These circumstances make it necessary to turn to the opportunities that project and problem learning provides.

\section{Research Questions}

The formation and source of the social capital due to issues: learning as a collective collaboration; project learning technologies; problem learning technology.

\section{Purpose of the Study}

The article is devoted to educational opportunities for the formation of social capital.

\section{Research Methods}

This study results from a theoretical understanding of the phenomenon of social capital and the practical implementation of methods for its formation in pedagogical activity. Articles and monographs on the essence and formation of social capital are studied and analyzed. The experience of project training in implementing the direction of training "Religious Studies" (Ural Federal University) is analyzed.

\section{Findings}

\subsection{Learning as a collective collaboration}

The most popular modern forms of interaction used in full-time and distance learning models are cooperation and collaboration. Collaboration, cooperation (from the Latin "co-operari") imply such an organization of the work of a team (team) in which the overall goal (task) is divided into individual subtasks. The result of the work appears as a sum of individual actions and a synergistic effect of interaction. At the same time, it is important that each team member clearly understands a single common goal, the degree of participation in the work, the value of contribution to implementing a common cause. Common cause involves the exchange of knowledge, experience, and resources (the principle of interdependence). Each team member should clearly understand the boundaries of personal responsibility for the final result (the principle of individual responsibility). The pedagogical skill of the teacher is to structure the tasks offered to the students in such a way that none of the team members could complete it only individually and help in assigning roles to each of the team members for performing joint actions (Gilyazova \& Zamoshchanskii, 2020; Mironova et al., 2019). Such training is based on many pedagogical concepts: 1) the concept of knowledge management, knowledge conversion; 2) conceptual provisions of cooperation pedagogy; 3 ) ideas of collective, joint activity, collegiality; 4) the provisions of the theory of communication since communication in this learning strategy is the primary tool for exchanging knowledge and experience.

In comparison with the focus on competition, individuality, independence of students, activity in a cooperative environment presupposes the involvement of students in the work of the team (and not only their motivation) and, thus, ensures a higher level of efficiency and productivity of the educational 
process. Newman defined student engagement as the investment of energy and effort in learning (Newmann, 1992). As a result of such training, each student performs the roles of both trainer and learner at the same time. As noted by Veledinskaya and Dorofeeva (2015), relying on the work of foreign researchers (Vaughan \& Garrison, 2005; Swan, 2004), in the parameters of the electronic educational environment, it is necessary to simulate the effect of "presence" in 24/7 mode. They distinguish three lines of educational interaction: "student-content", "student-teacher," "student-student" and, accordingly, three types of "presence" systems: cognitive presence, teaching "presence" (teaching presence and social presence. The content should be interactive and multimedia, have an understandable and convenient navigation and structure, influence various perception systems, create an imitation of presence in a real environment, assume prompt feedback, involve students in self-reflection, and an active attitude learning.

When the teacher chooses digital tools, it is necessary to pay attention to the following fact. There is a function of collaborative editing of the material - correcting participants' mistakes, commenting on the material, conducting an open discussion in the learning process: the ability to ask questions, edit assignments in real-time. To ensure the effective organization of interaction "student-teacher," it is necessary to provide the student with comprehensive training. Those elements that were most often formal in traditional education (learning outcomes, assessment system) acquire a special significance in distance learning (Perevalov et al., 2020; Tomyuk et al., 2019; Vaganova et al., 2020): detailed instructions on how to perform, assess assignments, criteria for peer review, samples, and best examples of implementation work. This circumstance helps students to determine the trajectory and pace of learning. Posts, short video messages, audio commentaries, recommendations for training materials help realize "presence" in the electronic environment. Convenient tools for team interaction and placement of various content are virtual interactive whiteboards (Padlet: https://ru.padlet.com/; Popplet: http://popplet.com/; FlockDraw: http://flockdraw.com/; Rizzoma: https://rizzoma.com/; Twiddla: https://www.twiddla.com/; Scrumlr: http://scrumblr.ca/; Miro: https://miro.com/).

When organizing training as a collaboration, the group (including the teacher) acts as a source of motivation, information, a means of help and mutual support, and interaction for the collective construction of knowledge. In order to organize effective communication in the learning process, the teacher must take into account the individual characteristics of students: openness, willingness to communicate / isolation, leadership qualities/willingness to obey, style of intellectual activity (erudite, critic, sceptic, generator of ideas, outsider). The division of students into groups for joint work can be done in various ways depending on the type of activity and learning tasks: randomly, according to the degree of sympathy, according to interests. The random method recreates real social situations in which a person rarely chooses colleagues or team members himself. This group formation allows students to develop social skills such as tolerance, respect, and understanding differences between people. The formation of groups at will, sympathy generates more trust, allowing more satisfaction from joint work. Considering the interests of students initiates their motivation and involvement in work. In distance learning, the teacher can create an input forum for self-presentation of students, discussion of expectations from training, conduct input and output questionnaires to compose a group portrait, identify problematic and interesting questions to initiate communication, compose tasks for mutual verification of works: mutual commenting, reviewing and evaluation. Use collaboration services. For example, Discord 
(http://discordapp.com), Trello (http://trello.com) - services for organizing project teams; Zoom (http://zoom.us) - a teleconferencing service; Kialo (http://www.kialo-edu.com), Klaxoon (http://klaxoon.com) - services for organizing discussions, debates and brainstorming; KAHOOT (http://kahoot.com) - a service of interactive mini-surveys that integrates into Office 365 Education; PeerGrade (http://www.peergrade.io) is a peer assessment organization service. In addition, in the strategy of teaching as cooperation, the teacher acts as an equal member of the educational team and is not the only bearer of knowledge. Therefore, a person must master the structures of mentoring that involve closer interaction: tutoring, support. The effectiveness of teaching as a collaboration directly depends, among other things, on the volume of the teacher's personal expenses both at the stage of developing an electronic course and in the process of accompanying the educational process.

\subsection{Project learning technologies}

Recently, in the modern school, within the framework of the competence-activity approach, more and more attention is being paid to developing the student's personality based on mastering universal methods of activity (universal educational actions). This block includes many different actions: from general education to actions related to the ability to formulate a problem and solve it. At the same time, the primary way of solving the problem is the ability to carry out a scientific, creative search independently, but, in the words of Dewey, it is "learning through doing." For domestic pedagogy, the problem of project technology in teaching is a traditional one, and Shatsky laid its origins in 1905. However, interest and active development of design technologies in school practice began to manifest itself only after the $60 \mathrm{~s}$ of the twentieth century actively. Based on its name, a practice-oriented project is of direct practical benefit not only to the student but also to society as a whole. Nevertheless, whatever type of project would be chosen by the student, as a result of its implementation, it is an independent search in solving this problem, attractive, cognitive for the development of personal qualities. The project activity continues during study at a higher educational institution.

Moreover, the student's project activity has even greater independence and creative activity, the development of "soft skills" competencies: the ability to think systematically, critically, to quickly respond to innovations in his specialty (the field of future work). Here are examples from the actual practice of teaching students in the specialty "Religious Studies" at the Department of Philosophy of the Ural Federal University named after the first President of Russia Yeltsin. Full-time students from the first year of study from the first semester are determined with the topic of the course project that interested them, with a focus on gradually, from various angles, exploring the chosen subject of study. Then the project manager who is most competent in the topic is determined. The importance of the project leader in university education is quite large - this is how the scientific ethos, scientific schools, scientific communities, and scientific communications begin to form. Student independence is one side of the issue; the other is scientific leadership. This project is a feature of project-based teaching technologies at a university, perhaps not so significant at the previous stage - in school education. So, there is a list of project topics, and there is a scientific advisor.

In the standards of 2011 and 2015 in the direction of "Religious Studies," the bachelor's level spelled out the types of activities for which graduates-religious scholars who have mastered the bachelor's 
program are prepared: research, pedagogical, organizational, and managerial activities (Ivanova et al., 2019). For the training and practical implementation of the first type of activity, course projects related to the active interaction of the student-scientific supervisor are provided. The scientific supervisor advises the young researcher, guides him in the necessary methodological direction since it is still challenging to navigate the methods applied in research in the first years. However, the ICT competence gained in the school educational process in the search for materials, in carrying out their research steps of studying their subject in the project, remains. An important point is the defence of the project in the students' team of their group with the teachers' presence. The reason is that project activity involves research, writing, design of the material, communication skills, the ability to discuss, constructive criticism, answers to questions asked, and listening to the interlocutor. This issue is how the competencies necessary for future professional activities are formed at both the bachelor and master's level. At the same time, projective teaching can be carried out not only as a defense of one's research project at the end of the year. However, it can be successfully applied in teaching religious studies in the form of "mini-research" on the problem posed by the teacher in his course (for example, on the history of religion). These are project-based work with literature, sources, documents on museum practice, group projects in the preparation of sociological research programs in the discipline "Sociology of Religion".

Naydis (2020) emphasizes that the project manager should be characterized by "the competence type T-Shaped, temporary competence, emotional intelligence, leadership qualities, and developed communication skills" (p. 20). In this case, the project itself is divided into parts. The planning of goals, tasks, and confirmation of the hypothesis takes place concerning the entire project. However, the development, verification, experimental confirmation will occur at the level of "subprojects," the results of which are called "increments." Thus, in the process of working in project activities, a graduate of a bachelor's and master's degree receives new personal qualities: (1) the ability to focus (concentrate) on a limited number of tasks, building a strategy of general team research; (2) commitment and responsibility for your area of work, the flexibility of thinking is one of the characteristics of creativity).

\subsection{Development trends of problem learning technology}

Problem-based learning is a pedagogical technology used today for developing students' social capital. The teacher-student interaction played an important role in forming a citizen and was inextricably linked with the accumulation of social capital, the integration of a person into social and political life. Today, the higher education system is inextricably linked with the technology of problem-based learning, which allows the formation of students' creative abilities to contribute to the formation of personality (Ibragimov, 2016) and implies some trends in its development:

1. Integration with information and computer training tools, the formation of special probleminteractive learning technology (Ibragimov, 2016) simplifies the interaction of training participants.

2. Generation of problem situations in the learning process that form modern competencies, including, which is very important for the accumulation of social capital, new communication methods for solving professional and personal problems (Ibragimov, 2016). 
3. Integration with other technologies (Ibragimov, 2016), including those that involve greater cooperation of students to solve educational problems and, therefore, contribute to the intensification of social capital formation.

In addition, a wide range of tasks was solved with the help of technology: 1. development of thinking; 2. formation of students' self-study skills; 3. motivation to learn; 4. development of creativity; 5. development of research skills; 6. development practical communication skills is generally developmental in determines its importance for the formation of social capital (Vaganova et al., 2019). Of the existing methods of problem learning (heuristic conversation, problem lecture, research method) at first glance, the latter has a greater social capital intensity. Problem learning is a system of problematic tasks, with the creative solution of which students learn methods of cognition, and therefore interact more with each other. However, the heuristic conversation is a dialogue, including questions, activating a creative approach to finding answers to them, and a problem lecture as a special arrangement of information by the lecturer, activating the independence of students' reasoning about what they heard, information assessment (Vaganova et al., 2019). The fact is that problematique as a constituent element of technology, in principle, activates students to turn to each other more often for clarifications and exchange of opinions, which cannot but affect their interaction and ultimately contribute to the growth of social capital.

\section{Conclusion}

The implementation of technologies focused on the development of social capital directly leads to the inclusion of students in an active cognitive process. Students themselves formulate the educational problem independently, collect the necessary information, plan possible solutions to the problem, draw conclusions, analyze their activities. A necessary result of training based on project and problem technologies is applying the knowledge gained in their further practical activities. Education becomes an instrument of orientation and construction by the student of an educational and life project. The choice of goals and the content and plan of action to achieve them are justified. Thus, this type of pedagogical technology has an educational and promising life strategy for the success of future specialists in the life search and construction of their destiny.

\section{References}

Bourdieu, P. (2012). Forms of capital. Economic Sociology, 5(3), 60-75.

Coleman, J. (1988). Social capital in the creation of human capital. American Journal of Sociology, 94, $95-120$

Coleman, J. (2001). Social and Human Capital. Social sciences and the present, 3, 121-126.

Fukuyama, F. (2004). Trust: social virtues and the path to prosperity. LLC "ACT Publishing House"; CJSC NPP "Ermak".

Gilyazova, O. S., \& Zamoshchanskii, I. I. (2020). On motivational tools of gamification in higher education: Theoretical aspect. Perspectives of Science and Education, 45(3), 39-51. https://doi.org/10.32744/pse.2020.3.3

Hanifan, L. J. (1916). The rural school community center. Annals of the American Academy of Political and Social Science, 67, 130-138. https://doi.org/10.1177/000271621606700118 
Ibragimov, G. I. (2016). Problematic education in the system of higher education: state and development trends. Bulletin of the Buryat State University. Education. Personality. Society, 1, 17-26.

Ivanova, E. V., Kuznetsova, O. V., \& Melnikova, E. V. (2019). State educational standards (undergraduate level) on the professional activities of study of religious scholar and theologian: characteristics and changes. Perspectives of Science and Education, 42(6), 55-64. https://doi.org/10.32744/pse.2019.6.5

Mironova, M. V., Smolina, N. S., \& Novgorodtseva, A. N. (2019). Inclusive education at school: Contradictions and problems of organizing an accessible environment (for example, schools in the Russian Federation). Perspectives of Science and Education, 6(42), 349-359. https://doi.org/10.32744/pse.2019.6.29

Naydis, I. O. (2020). AGILE method in project management: implementation of the method, the competence of the team and the project manager. Bulletin AGTU: Economics, 4, 15-24.

Newmann, F. (1992). Student Engagement and Achievement in American Secondary Schools. Teachers College Press.

Perevalov, V. D., Novgorodtseva, A. N., Sivkova, N. I., Korelin, A. V., \& Korelina, E. V. (2020). Digitalization of Russian higher education: Educational process technologies (experience of universities of the Ural Federal District of Russian Federation. Perspectives of Science and Education, 46(4), 36-46. https://doi.org/10.32744/pse.2020.4.3

Putnam, R. (1996). For Democracy to Work. Ad Marginem.

Swan, K. (2004). Relationships Between Interactions and Learning in Online Environments. The Sloan Consortium. Retrieved on $5^{\text {th }}$ of October from: https://www.immagic.com/eLibrary/ARCHIVES/GENERAL/SLOANCUS/S041202C.pdf? cf c hl managed tk =pmd .hxKxZ25zdldial9.aZFXWftYsynWuyTMxyjdloQH74-1633413070-0gqNtZGzNAuWjenBszRNl

Tomyuk, O. N., Dyachkova, M. A., Kirillova, N. B., \& Dudchik, A. Yu. (2019). Digitalization of the educational environment as a factor of personal and professional self-determination of students. Perspectives of Science and Education, 42(6), 422-434.

Vaganova, O., Gilyazova, O. S., Gileva, A., Yarygina, N. A., \& Bekirova, E. S. (2020). Quality management of educational activities in higher education. Amazon investigates, 9(28), 74-82. https://doi.org/10.34069/AI/2020.28.04.9

Vaganova, O. I., Maksimova, K. A., \& Karpova, M. A. (2019). Problem-based learning technology in vocational education. Karelian Scientific Journal, 8(4), 7-10.

Vaughan, N., \& Garrison, D. R. (2005). Creating a cognitive presence in a blended faculty development community. Internet and Higher Education, 8, 1-12.

Veledinskaya, S. B., \& Dorofeeva, M. Yu. (2015). Effective support of e-learning: technologies for involving and retaining students. Educational technologies, 3, 104-115. 